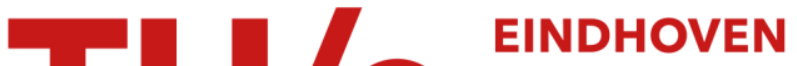 UNIVERSITY OF TECHNOLOGY
}

\section{Static and dynamic control of fingerprint landscapes of liquid crystal network coatings}

\section{Citation for published version (APA):}

Feng, W., Broer, D. J., Grebikova, L., Padberg, C., Vancso, J. G., \& Liu, D. (2020). Static and dynamic control of fingerprint landscapes of liquid crystal network coatings. ACS Applied Materials \& Interfaces, 12(5), 5265-5273. https://doi.org/10.1021/acsami.9b11928

DOI:

10.1021/acsami.9b11928

Document status and date:

Published: 05/02/2020

\section{Document Version:}

Accepted manuscript including changes made at the peer-review stage

\section{Please check the document version of this publication:}

- A submitted manuscript is the version of the article upon submission and before peer-review. There can be important differences between the submitted version and the official published version of record. People interested in the research are advised to contact the author for the final version of the publication, or visit the $\mathrm{DOI}$ to the publisher's website.

- The final author version and the galley proof are versions of the publication after peer review.

- The final published version features the final layout of the paper including the volume, issue and page numbers.

Link to publication

\section{General rights}

Copyright and moral rights for the publications made accessible in the public portal are retained by the authors and/or other copyright owners and it is a condition of accessing publications that users recognise and abide by the legal requirements associated with these rights.

- Users may download and print one copy of any publication from the public portal for the purpose of private study or research.

- You may not further distribute the material or use it for any profit-making activity or commercial gain

- You may freely distribute the URL identifying the publication in the public portal.

If the publication is distributed under the terms of Article 25fa of the Dutch Copyright Act, indicated by the "Taverne" license above, please follow below link for the End User Agreement:

www.tue.nl/taverne

Take down policy

If you believe that this document breaches copyright please contact us at:

openaccess@tue.nl

providing details and we will investigate your claim. 


\title{
Static and Dynamic Control of Fingerprint Landscapes of Liquid Crystal Network Coatings
}

\author{
Wei Feng, ${ }^{\dagger, \ddagger}$ Dirk J. Broer, ${ }^{\dagger, \ddagger \S}$ Lucie Grebikova, "Clemens Padberg," Julius G. Vancso, \\ and Danqing Liu*, $*,+, \S(0)$
}

${ }^{\dagger}$ Laboratory of Stimuli-responsive Functional Organic Materials \& Devices (SFD), Department of Chemical Engineering \& Chemistry, and ${ }^{\ddagger}$ Institute for Complex Molecular Systems (ICMS), Eindhoven University of Technology, Groene Loper 5, Eindhoven 5612 AE, The Netherlands

${ }^{\S}$ SCNU-TUE Joint Lab of Devices Integrated Responsive Materials, South China Normal University, No. 378, West Waihuan Road, Guangzhou Higher Education Mega Center, Guangzhou 510006, China

"Materials Science and Technology of Polymers, Faculty of Science and Technology, MESA+ Institute for Nanotechnology, University of Twente, Enschede 7500 AE, The Netherlands

Supporting Information

ABSTRACT: Surface topography variations of liquid crystal networks in their functional coatings provide unique properties in these systems. Chiral-nematic polymer coatings self-organize in a fingerprint texture with the molecular helices parallel to the substrate with alternating domains of molecular units with parallel

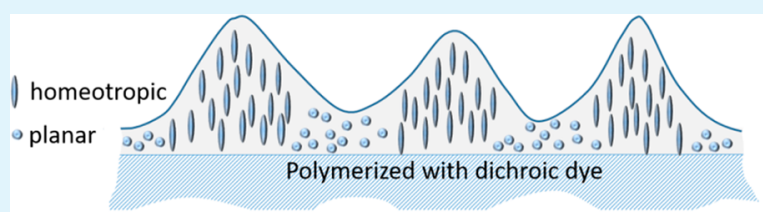
and perpendicular director orientation as controlled by the concentration of a reactive chiral additive. Driven by surfacetension differences and altered by anisotropic polymerization shrinkage, the coating may form hills and valleys hundreds of nanometers in size with different molecular alignment. The director orientation in the corrugations could be controlled by monomer diffusion during polymerization. Polymerization in the presence of a dichroic dye gives topographic elevations in which the molecules

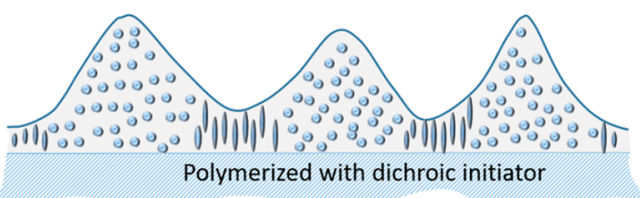
are oriented along the normal. Polymerization by means of a dichroic photoinitiator gives topographic elevations in which the molecules align parallel to the surface. By balancing the monomer diffusion and anisotropic polymerization shrinkage, relatively flat surfaces are also achieved. The different surfaces exhibit distinct topographical deformations when subjected to external stimuli, such as an AC electric field. This method can be universally extended to LC polymers with other alignment configurations.

KEYWORDS: dichroic molecules, surface topography, liquid crystal networks, fingerprint, electric field

\section{INTRODUCTION}

Functional surfaces that can dynamically change from one state to another state have attracted intensive attention recently because of their applications in various functions, for instance, self-cleaning, ${ }^{1,2}$ haptics, ${ }^{3}$ directional movement, and transportation of objects. ${ }^{4-6}$ A large part of surface functionality is influenced by the topography of surface coatings and impressive functions are achieved with the aid of the surface topographical characteristics. As a next step, dynamic surface topographies actuated by external stimuli are anticipated to lead to new functions, ${ }^{7}$ such as switchable adhesion, ${ }^{8-10}$ tunable optical properties, ${ }^{11-14}$ and microfluidic manipulation. ${ }^{2,15}$ Convenient stimuli studied to actuate the surfaces can be either light, ${ }^{8,16-18}$ heat $^{19-21}$ or electrical input. ${ }^{22,23}$ In particular, as anisotropic materials, liquid crystal networks (LCNs) and liquid crystal elastomers (LCEs) respond to the stimuli with order parameter reduction and affording mechanical deformation, contributing to their capability in performing various tasks. ${ }^{24-31}$ An important class of responsive LCNs are chiral-nematic polymer networks in which the average molecular orientation, defined by the director, described a helix. Especially when the helix axis is chosen to be parallel to the surface, interesting and unique fingerprint textures are formed that are capable of performing a number of tasks such as controlling friction, grip, and removal of dust and particles. ${ }^{4,8}$ However, in many cases, because of the Marangoni effect $^{32}$ explaining surface-energy-related material transportation and anisotropic shrinkage during polymerization, ${ }^{33}$ the fingerprint LC polymer coatings are decorated with intrinsic nonflat surface topographies, which are depending on the application sometimes desired and in other cases undesired. It

Special Issue: Young Investigator Forum

Received: July 8, 2019

Accepted: August 27, 2019 

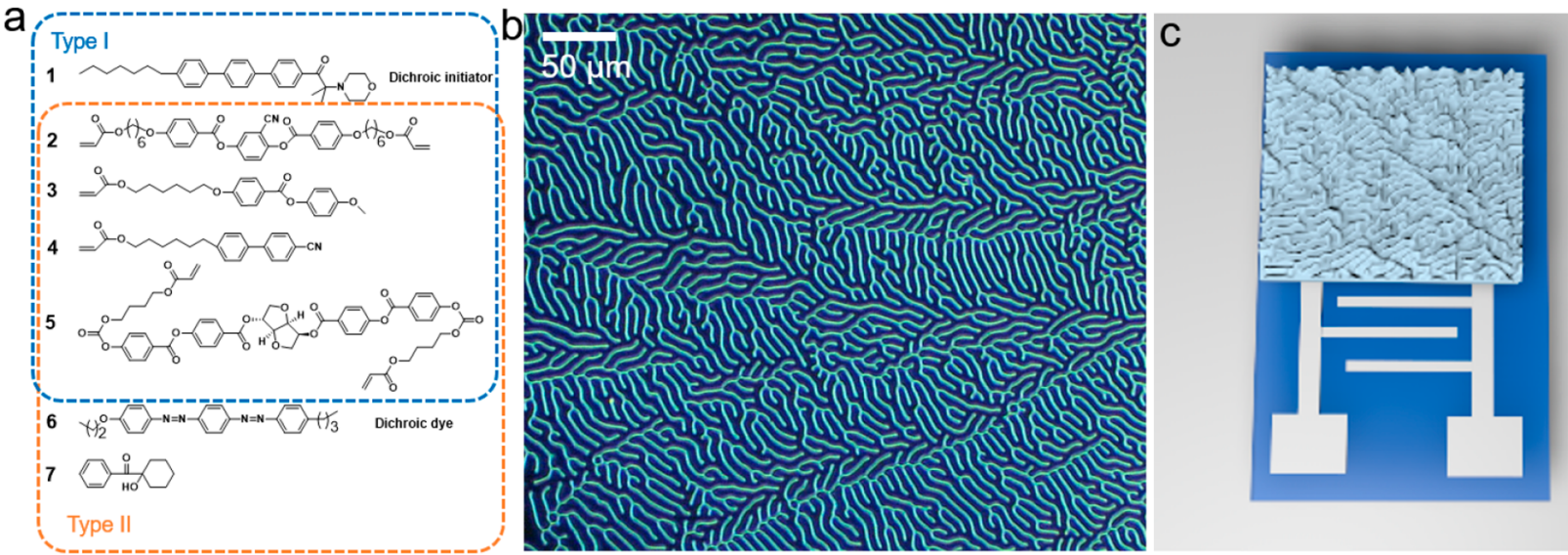

Figure 1. (a) Chemical structures of monomer used for different types of LCN coatings. (b) A typical fingerprint texture under the polarized optical microscope. (c) Illustrative device configuration containing interdigitated electrodes for actuation of LCN surface topography. The width of the electrode and the gap between adjacent electrodes is $10 \mu \mathrm{m}$.

is therefore important, despite many studies about the tuning of the orientation, handedness and pitch of the chiral nematic LC systems, ${ }^{34-39}$ to study the mechanism of the formation of the fingerprint topographies and to control them during the formation or by an active actuation after the formation of the LCN coating.

In this article, we first monitored the fingerprint topographical structure prior to and during polymerization of the chiral LCN using the digital holographic microscope (DHM). After understanding the mechanism of their formation, we demonstrate the control of the coating surface topography during its preparation by photopolymerization by means of dichroic absorption phenomena exploiting the periodic alternation of the molecular orientation in the fingerprint texture. Finally, we demonstrate switching by either an enhancement of the corrugations or an inversion of the structure by the application of an in-plane electrical field.

\section{EXPERIMENTAL SECTION}

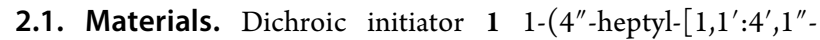
terphenyl]-4-yl)-2-methyl-2-morpholinopropan-1-one) was obtained from Philips Research Laboratories. Reactive liquid crystal monomers 2 (2-cyano-1,4-phenylene bis(4-((6-(acryloyloxy)hexyl)oxy)benzoate), 3 (4-methoxyphenyl 4-((6-(acryloyloxy)hexyl)oxy)benzoate), and 4 (6-(4'-cyano-[1,1'-biphenyl]-4-yl)hexyl acrylate)were obtained from Merck GmbH. Chiral dopant 5 ((3R,3aS,6S,6aS)hexahydrofuro[3,2- $b]$ furan-3,6-diylbis (4-((4-(((4) acryloyloxy)butoxy)carbonyl)oxy)benzoyl)oxy)benzoate) was purchased from BASF. Dichroic dye 6 (1-(4-butylphenyl)-2-(4-((4-propoxyphenyl)diazenyl)phenyl)diazene) was obtained from Hayashibara Biochemical Laboratories, INC., Japan. Initiator 7 ((1-hydroxycyclohexyl)(phenyl)methanone, IRGACURE 184) was purchased from Ciba. LC monomers were mixed in the weight ratio of $2: 3: 4=10: 50: 40$.

2.2. Fabrication. Glass substrates were cleaned by sonication in acetone and isopropanol for $10 \mathrm{~min}$, respectively, and dried under $\mathrm{N}_{2}$. The polyimide SE 7511L (Nissan Sunever) was spin-coated onto the substrate at a speed of $5000 \mathrm{rpm}$ and then baked at $100{ }^{\circ} \mathrm{C}$ for $10 \mathrm{~min}$ and $200{ }^{\circ} \mathrm{C}$ for $90 \mathrm{~min}$. The LC monomers mixture was dissolved in THF and spin-coated on the substrate. Sometimes, a unidirectional low-pressure buffing on the polyimide layer prior to processing LC monomer mixture was applied to create more regular line structures. Subsequently, the coating was photopolymerized in a $\mathrm{N}_{2}$ atmosphere by UV illumination from the top of the samples (Ominicure EXFO S2000). A two-step photopolymerization was carried out: monomeric coatings were first illuminated with UV light with designated intensities for $30 \mathrm{~min}$ to enable materials diffusion, then they were exposed to strong UV light $\left(50 \mathrm{~mW} \cdot \mathrm{cm}^{-2}\right)$ for $20 \mathrm{~min}$ to fully cure the monomers. A postcure was performed at $120^{\circ} \mathrm{C}$ for $10 \mathrm{~min}$. The final thickness of LCN coatings depends on the fingerprint pitch; the thickness of coating with pitch $=30 \mu \mathrm{m}$ fingerprint was $4.5 \mu \mathrm{m}$.

2.3. Characterization. Surface topographies of LCN coatings were mapped with Digital Holographic Microscope (Lyncee Tech, Switzerland). The textures and alignment of samples were checked with microscope with crossed polarizers (Leica DM2700). The local mechanical properties of different domains in the LCN coating were studied with an atomic force microscope (AFM) with nanoindentation. ${ }^{40}$ The AFM measurements were carried out in the air in the PeakForce Quantitative Nanomechanical Mapping (QNM) mode by the Multimode 8 AFM with the NanoScope V controller (Bruker, USA). The cantilevers (OMCL-AC240TS, Olympus, Japan) had a nominal tip radius smaller than $8 \mathrm{~nm}$, a resonance frequency of $70 \mathrm{kHz}$ in air and spring constant $2.3 \mathrm{~N} / \mathrm{m}$, as measured by thermal fluctuations in air. ${ }^{41}$ The AFM piezo oscillated at $0.5 \mathrm{kHz}$ and forcedistance curves were captured each time the AFM tip tapped on the sample surface. The values of Young's moduli were determined with reference to a material of a known Derjaguin-Muller-Toporov (DMT) elastic modulus by using so-called "relative method" based on a simplified DMT formalism. In the "relative method", mechanical properties of a sample under investigation are compared to a known, well-defined polystyrene reference sample with Young's modulus of 2.7 GPa (Bruker, USA). All AFM experiments were performed at room temperature of $20{ }^{\circ} \mathrm{C}$ with a stable humidity of $40 \%$. The indentation depth (sample deformation) was controlled to be typically about $5 \mathrm{~nm}$. The image processing and the data evaluation were performed with the NanoScope Analysis 1.9 software.

\section{RESULTS AND DISCUSSION}

3.1. Marangoni Effect in the Monomeric State and Anisotropic Polymerization Shrinkage. It has been demonstrated that low molecular weight chiral mixtures of cyanobiphenyl-based liquid crystals, when applied on a rubbed substrate with their other interface to air, form fingerprints textures with periodic corrugations in phase with the pitch of the planar chiral-nematic helix. ${ }^{4}$ Similar structures were found in fingerprint liquid crystal network coatings. ${ }^{8,22}$ The surface tension forces (Marangoni effect), eventually combined with the splay, bend and twist elastic forces within the liquid crystal, reduce the system's free energy by forming spontaneous corrugations corresponding to the director periodicity. To demonstrate this effect for our LCNs, we made mixtures of nematic LC monomers $2-4$ and chiral additive 5 and photoinitiator 1 or 7 . Dissolved in THF the mixtures were 


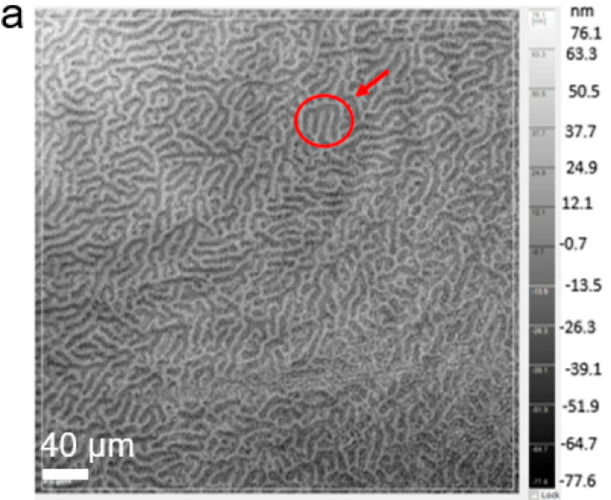

Before polymerization

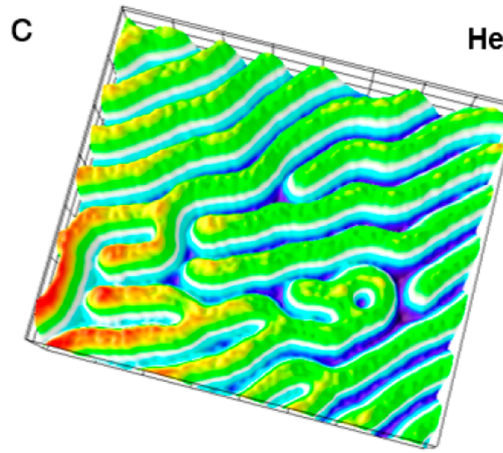

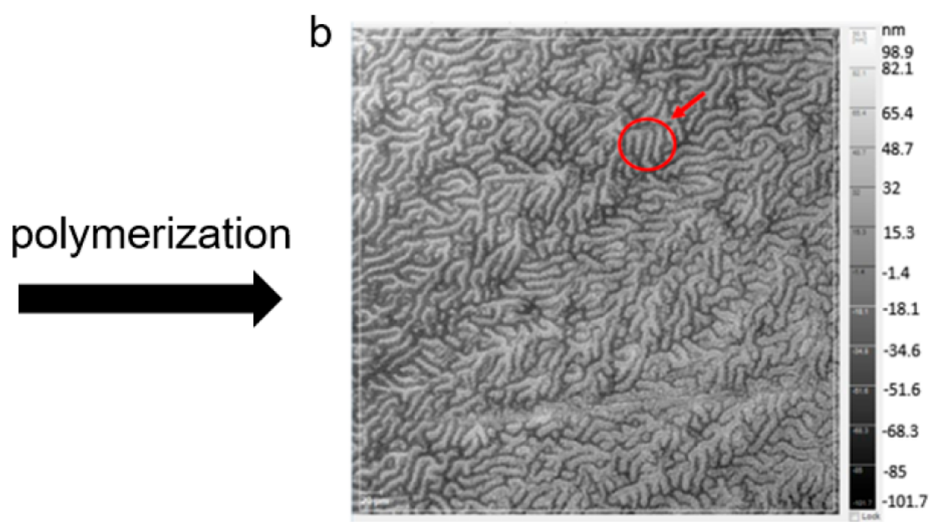

After polymerization
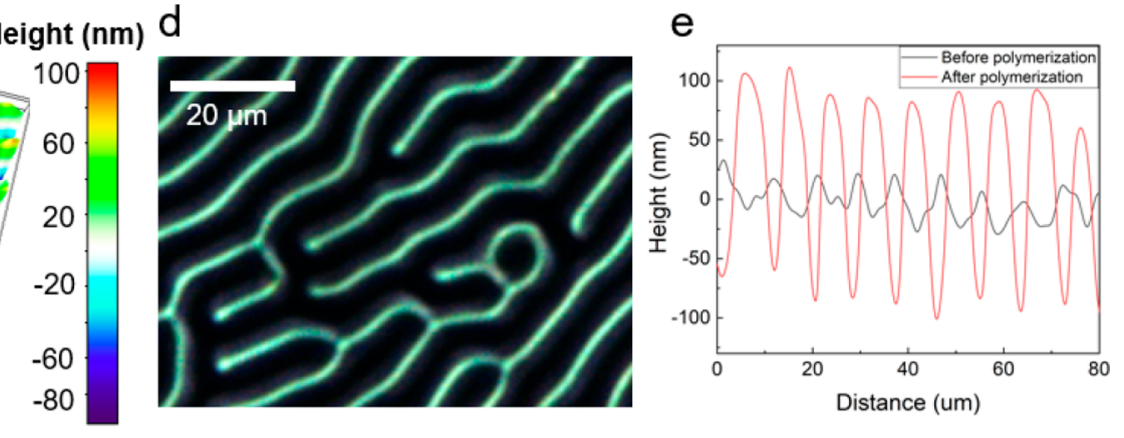

Figure 2. Topography inversion in the polymerization process. (a) Monomeric state before polymerization. (b) After polymerization. The gray scale indicates the topographical height of the fingerprint patterns. (c) Correlated topography of the polymer LCN coating and (d) the corresponding POM image. (e) 2D topographical profiles.

spin-coated on a substrate coated with a homeotropic aligning polyimide. After evaporation of the solvent, a film is obtained with a thickness of $4.5 \mu \mathrm{m}$. The fingerprint configuration is formed under the twisting force of monomer $\mathbf{5}$ and the homeotropic anchoring force of the polyimide layer. A typical texture of the still monomeric mixture as observed by polarizing optical microscope (POM) between crossed polarizers is shown in Figure 1b. By dynamic holographic microscopy a surface profile of the monomeric coating could be made (Figure 2a). By carefully correlating the POM with the DHM images of the same surface area, as is shown in Figure $2 \mathrm{~b}, \mathrm{c}$ and gratefully benefiting from the uniqueness of the fingerprints, we could determine that the molecular director in the hills and the valleys of the corrugations. At the top of the hills, the director is perpendicular toward the air surface (homeotropic following the liquid crystal nomenclature) and in the valleys the director is planar with the average long axes of the molecules parallel to the air surface. The confinement of the molecules in the helix configuration, align the molecules also perpendicular to the helix axes, which in our case also means parallel to the topographical ridges. The height of the corrugations in the monomeric state is around 30 to 50 $\mathrm{nm}$ (Figure 2a, e).

The surface topographical deformation during polymerization was in situ probed with DHM at room temperature (25 ${ }^{\circ} \mathrm{C}$ ). During polymerization conducted in the presence of $2 \mathrm{wt}$ $\%$ isotropic photoinitiator 7 , the topography was observed to become inverted. When the polymerization has been completed, we find the planar domains are higher than the homeotropic domains. The height difference value now reaches to about $150-200 \mathrm{~nm}$. The topographic inversion is confirmed by the correlated texture in POM image and the topography image (Figure $2 \mathrm{c}, \mathrm{d}$ ). The explanation can be found in polymerization shrinkage. Typically, the liquid crystal monomers, due to the conversion of van der Waals distances to covalent bond distances, exhibit a volume shrinkage of around $4-6 \%$ during polymerization, ${ }^{33}$ and simultaneously it was found that the shrinkage predominantly occurs along the director of the LC mixtures. In our system it means that the shrinkage in the homeotropic area is larger than in the planar area. In other words, the initially higher area shrinks more than the lower area and ultimately leads to the height inversion.

3.2. System I Coating: Polymerization Initiated by a Dichroic Photoinitiator. Dichroic species of anisotropic molecular shape have their large directional transition moment often parallel to their long molecular axes, thus largely interacting with the electrical field vector of light incoming along the normal to the coating surface. Consequently, when embedded in a fingerprint chiral-nematic matrix, dichroic molecules that follow the liquid crystal director have a large absorption when they are in the planar area of the molecular helix and a low absorption when they are in the perpendicular (homeotropic) area. Applying this dichroic optical property to the photoinitiator 1 promotes the polymerization to occur in the planar domains. Consuming the monomers faster in these regions stimulates concentration-gradient induced diffusion of the still unreacted monomer from the homeotropic area to the planar area. This will increase the volume of the planar area as no counter diffusion of the polymerized monomer takes place. Consequently, a relative expansion will take place in the $z$ direction perpendicular to the surface, resulting in the topographically higher planar domains. 

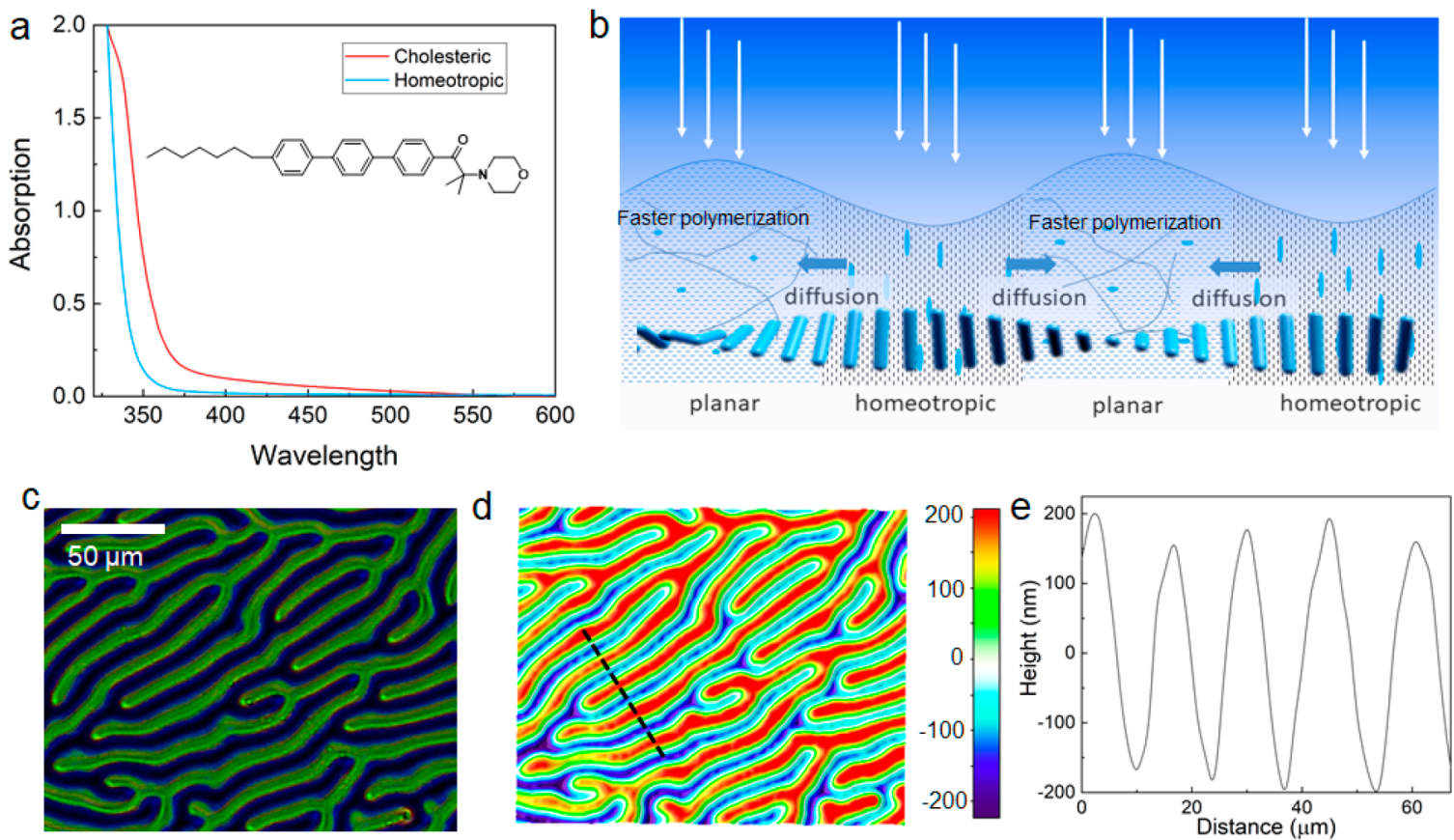

Figure 3. (a) UV-vis absorption spectra of dichroic initiator for nonpolarized light in cholesteric and homeotropic LC hosts. (b) Schematic illustration of the formation of system I coating. Because of material diffusion from homeotropic to planar domains and larger polymerization shrinkage in homeotropic domains, planar domains are higher than homeotropic domains. The white arrows represent the propagation direction of the light. (c) POM image between crossed polarizer. (d) Correlated surface topography image with the digital holographic microscope (DHM). The planar domains are higher than homeotropic domains. (e) $2 \mathrm{D}$ cross-section surface topography profile.
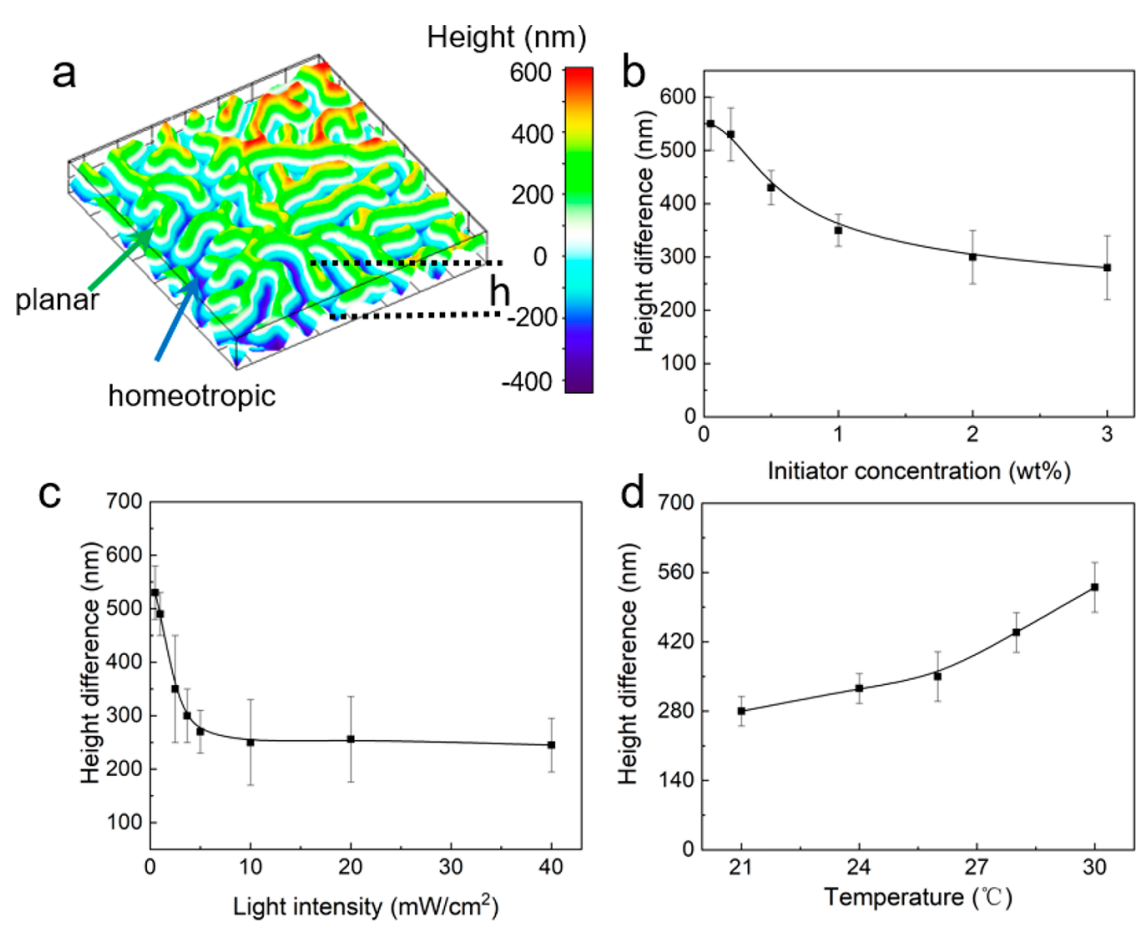

Figure 4. (a) Illustration of the quantification of the height difference between the planar and homeotropic domain. (b) Influence of dichroic initiator concentration on the height difference. Fixed parameters: light intensity $0.5 \mathrm{~mW} \mathrm{~cm}{ }^{-2}$, temperature $30{ }^{\circ} \mathrm{C}$. (c) Influence of light intensity on the height difference. Fixed parameters: $0.2 \mathrm{wt} \%$ dichroic initiator, polymerization temperature $30{ }^{\circ} \mathrm{C}$. (d) Influence of polymerization temperature on the height difference. Fixed parameters: $0.2 \mathrm{wt} \%$ dichroic initiator; light intensity, $0.5 \mathrm{~mW} \mathrm{~cm}$.

To investigate the different light absorption of dichroic initiator in different domains, its dichroic behavior for the nonpolarized light was checked using a cholesteric sample and a homeotropic sample. The LC host for mixing the dichroic initiator consists of 10 wt \% 2, 50 wt \% 3, 40 wt \% 4. For the cholesteric sample, additionally the chiral dopant 5 was added ( 1 wt \% of LC host). From the UV-vis spectra (Figure 3a) of the samples still in their monomeric state, the dichroic ratio ( $A_{\text {cholesterid }} / A_{\text {homeotropic }}$ ) of the dichroic photoinitiator $\mathbf{1}$ is 5.5 at $365 \mathrm{~nm}$, indicating a good alignment of dichroic photoinitiator 


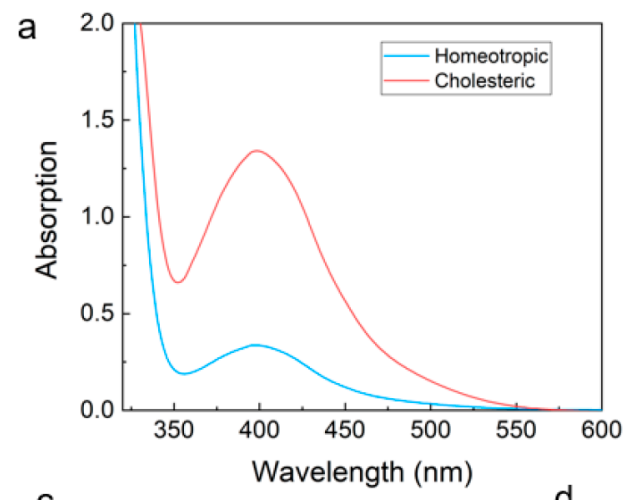

C

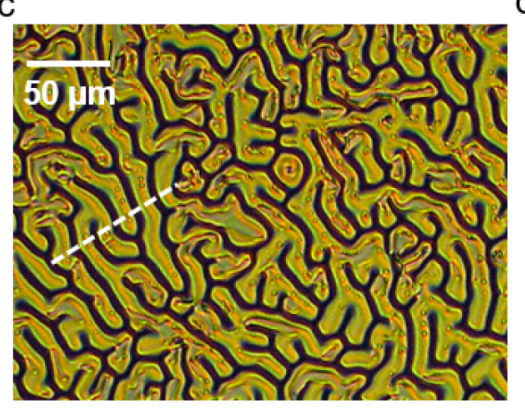

b

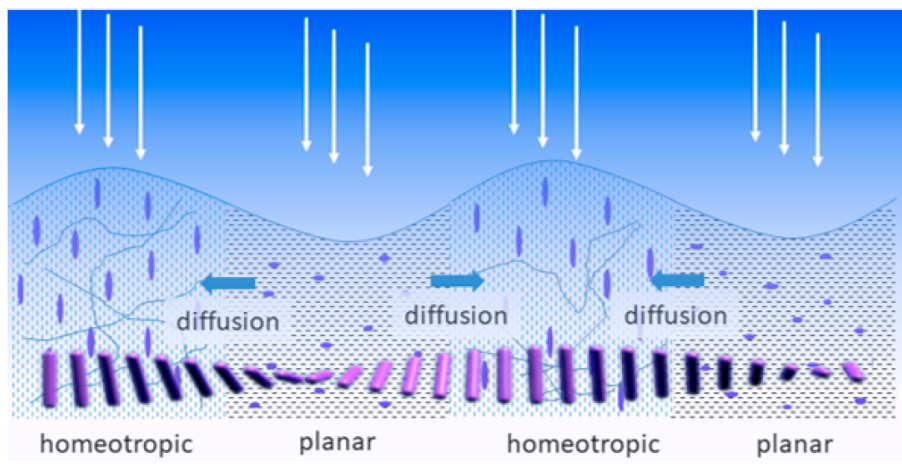

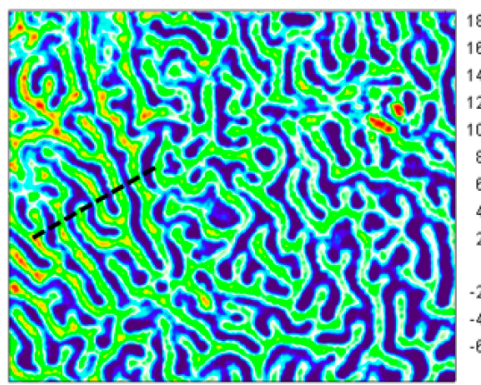

$\mathrm{e}_{200}$
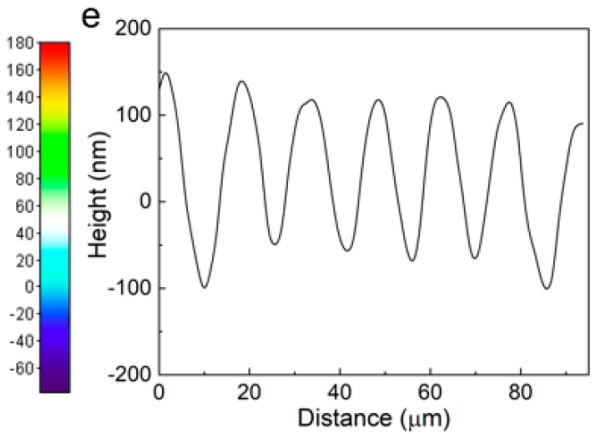

Figure 5. (a) UV-vis absorption spectra of dichroic dye for light polarized parallel and perpendicular to the LC director. (b) Schematic illustration of the formation of system II fingerprint LCN coating. Because of material diffusion from planar to homeotropic domains, homeotropic domains are higher than planar domains. White arrows represent the propagation direction of the light. (c) POM image and (d) the correlated surface topography. Planar domains are lower than homeotropic domains. (e) $2 \mathrm{D}$ cross-section surface topography profile.

1 with the LC monomers. Following conventional free radical polymerization kinetics, the rate of free-radical photopolymerization scales with the root of the absorbed light intensity of the initiator. This is usually the case in the initial state of the polymerization. The difference in polymerization rate becomes even enhanced by the Trommsdorff effect at somewhat higher conversion where the termination reaction becomes suppressed by limited polymer chain mobility. When applied to our fingerprints with the helix axes parallel to the surface, the monomer conversion proceeds much faster in the planar domains than homeotropic domains and creates a periodic monomer concentration gradient following the helix contour, especially the fast consumed diacrylates. Consequently, LC monomers diffuse from homeotropic domains to planar domains as is schematically shown in Figure $3 \mathrm{~b}$.

The fingerprint LCN coatings we produced by means of the dichroic photoinitiator $\mathbf{1}$ we nominate as the system I coatings. In the monomeric state of the coatings the valleys are filled with the planar-aligned molecules. Polymerization with a nondichroic photoinitiator leads to height inversion and a corrugation depth of $150 \mathrm{~nm}$. Now by polymerizing in the presence of the dichroic photoinitiator the height difference becomes even more pronounced as follows from the characterization of the same sample area using POM and DHM (Figure 3c-e). For clarity, we define $\mathbf{h}$ as the height difference between the planar and homeotropic domains (Figure 4a); its value is positive when planar domains are higher than the homeotropic domains. With slow polymerization rate to allow material diffusion at certain polymerization conditions (which will be discussed later in Figure 4), we can see that the nonbirefringent homeotropic domains are lower than the birefringent planar domains with a height difference $\mathbf{h}$ around $400 \mathrm{~nm}$. Compared with the initial topography before polymerization where the homeotropic domains are $50 \mathrm{~nm}$ higher than planar domains, the relative height between homeotropic and planar domains changes by $450 \mathrm{~nm}$ in the polymerization process.

To gain better control over the height difference, the impact of dichroic initiator concentration, UV light intensity and polymerization temperature on the height difference between planar and homeotropic domains were investigated. In detail, on one hand, by varying the dichroic initiator concentration with keeping the UV light intensity constant $\left(0.5 \mathrm{~mW} \cdot \mathrm{cm}^{-2}\right)$ or varying the UV light intensity while keeping the dichroic initiator concentration constant $(0.2 \mathrm{wt} \%)$, the height difference is larger in the small initiator concentration or low light intensity regime, where the polymerization rate is relatively low and more materials diffusion is permitted (Figure $4 \mathrm{~b}, \mathrm{c})$. On the other hand, when the initiator concentration is above 1 wt \% or the light intensity is stronger than $5 \mathrm{~mW}$. $\mathrm{cm}^{-2}$, no further change in height difference is observed with higher initiator concentration and light intensity. It is speculated that, at high initiator concentration and strong UV light intensity regime, the polymerization and cross-linking in homeotropic domains proceeds fast and inhibits the material diffusion from homeotropic to planar domains. At these conditions (large initiator concentration (>2 wt \%) and strong UV light intensity $\left.\left(5 \mathrm{~mW} \cdot \mathrm{cm}^{-2}\right)\right)$, the height difference is mostly contributed by the different polymerization shrinkage in homeotropic and planar domains. As for the influence of polymerization temperature, the height difference is observed to be larger at higher polymerization temperatures while other experimental parameters are kept constant (dichroic initiator concentration and UV light intensity are kept at $0.2 \mathrm{wt} \%$ and $0.5 \mathrm{~mW} \cdot \mathrm{cm}^{-2}$, respectively) (Figure $4 \mathrm{~d}$ ). In the experiment, we 

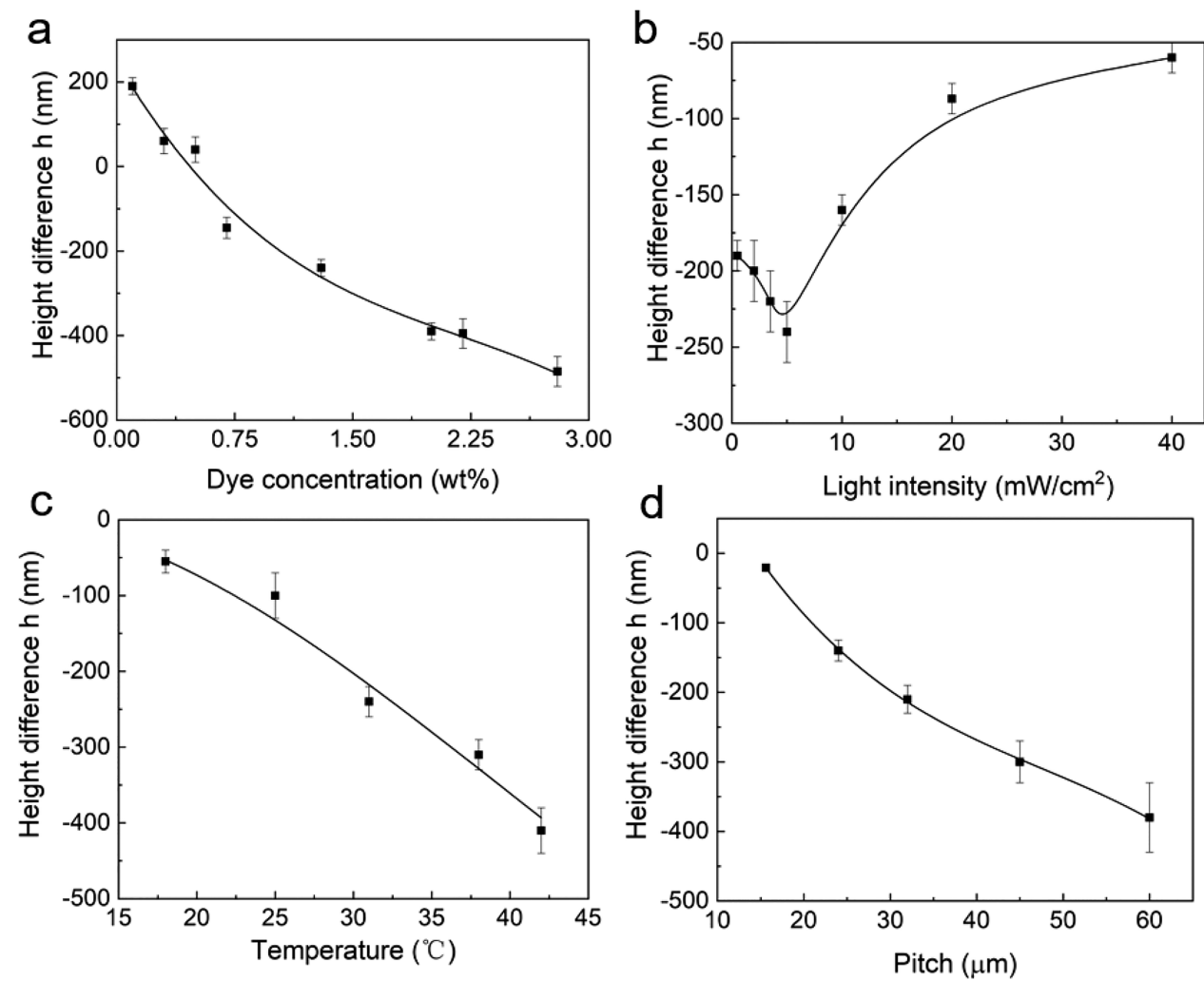

Figure 6. (a) Influence of dichroic dye concentration on the height difference. Fixed parameters: light intensity $5 \mathrm{~mW} \mathrm{~cm}^{-2}$, temperature $30{ }^{\circ} \mathrm{C}$. (b) Influence of light intensity on the height difference. Fixed parameters: $1.3 \mathrm{wt} \%$ dichroic dye, polymerization temperature $30{ }^{\circ} \mathrm{C}$. (c) Influence of polymerization temperature on the height difference. Fixed parameters: $1.3 \mathrm{wt} \%$ dichroic dye concentration, light intensity $5 \mathrm{~mW} \mathrm{~cm}^{-2}$. (d) Height difference $h$ as a function of the fingerprint pitch. Polymerization condition: 2 wt \% dichroic dye, $5 \mathrm{~mW} \mathrm{~cm}^{-2} \mathrm{UV}$ light illumination, polymerization temperature $30^{\circ} \mathrm{C}$.

selected temperature range to avoid crystallization and dewetting of the LC monomer coating.

3.3. System II Coating: Photopolymerization in the Presence of Dichroic dye. Next, we fabricated a different type of coatings (system II) by using the nondichroic photoinitiator 7 in the presence of dichroic dye 6 . When the anisotropic light absorption is regulated by a dichroic dye, the photoinitiator will experience a lower UV light intensity in the planar regions. This slows down polymerization in planar domains and induces a concentration gradient-induced monomer diffusion and consequently the formation of elevated regions with homeotropic director orientation.

Similar to the investigation of the dichroic ratio of dichroic initiator $\mathbf{1}$ in section 3.2, the dichroism of dichroic dye $\mathbf{6}$ is revealed with a cholesteric sample and a homeotropic sample. The dichroic ratio $\left(A_{\text {cholesteric }} / A_{\text {homeotropic }}\right)$ is calculated to be 4.0 at absorption peak $398 \mathrm{~nm}$ (Figure 5a), indicating that the dichroic dye exhibits stronger absorption to the light polarized parallel to its molecular long axis. Therefore, in fingerprintconfigured LC coating, the dye has larger absorption of the normally incident light in planar domains than in the homeotropic domains. Consequently, the photoinitiator will experience an overall lower light intensity in the planar domains. This results in slower polymerization in the planar domains than in the homeotropic domains (Figure 5b). The faster conversion of LC monomers in the homeotropic domains induces diffusion to the homeotropic domains leading to local expansion. Although the polymerization shrinkage is larger in the homeotropic domains than in planar domains, the material diffusion dominates over the effect of polymerization shrinkage in this case.

Correlating the POM textures and the surface topography from DHM (Figure $5 \mathrm{c}-\mathrm{e}$ ) proves that the homeotropic domains are higher than the birefringent planar domains. The height difference $h$ is around $-200 \mathrm{~nm}$ (coming from $-50 \mathrm{~nm}$ before polymerization). To investigate the influencing factors on the height difference between homeotropic and planar domains in the prepared coating, several parameters including dichroic dye concentration, light intensity and polymerization temperature were studied. The results show that the height difference $h$ decreases monotonically with increased dichroic dye concentration, whereas all other factors remain the same (UV light intensity: $5 \mathrm{~mW} \mathrm{~cm}{ }^{-2}$, polymerization temperature: $30{ }^{\circ} \mathrm{C}$ ) (Figure $6 \mathrm{~b}$ ).

Notably, a critical point of the dichroic dye concentration was found where $h=0$. In that case a flat coating surface is obtained. When the dichroic dye concentration $(0.1-0.3 \mathrm{wt}$ $\%)$ is lower than a certain threshold, the $h$ value is positive and homeotropic domains are lower than planar domains. This is attributed to a dominancy of the anisotropic polymerization shrinkage effect over the concentration gradient-induced material diffusion due to the relatively weak light absorption of the dichroic dye. Comparatively, with a higher concentration of dichroic dye, more light can be absorbed by dichroic dye molecules in planar domains, inducing slower polymerization initiation and more monomer diffusion from planar to homeotropic domains, resulting in smaller height difference $h$ value (Figure 6a). 

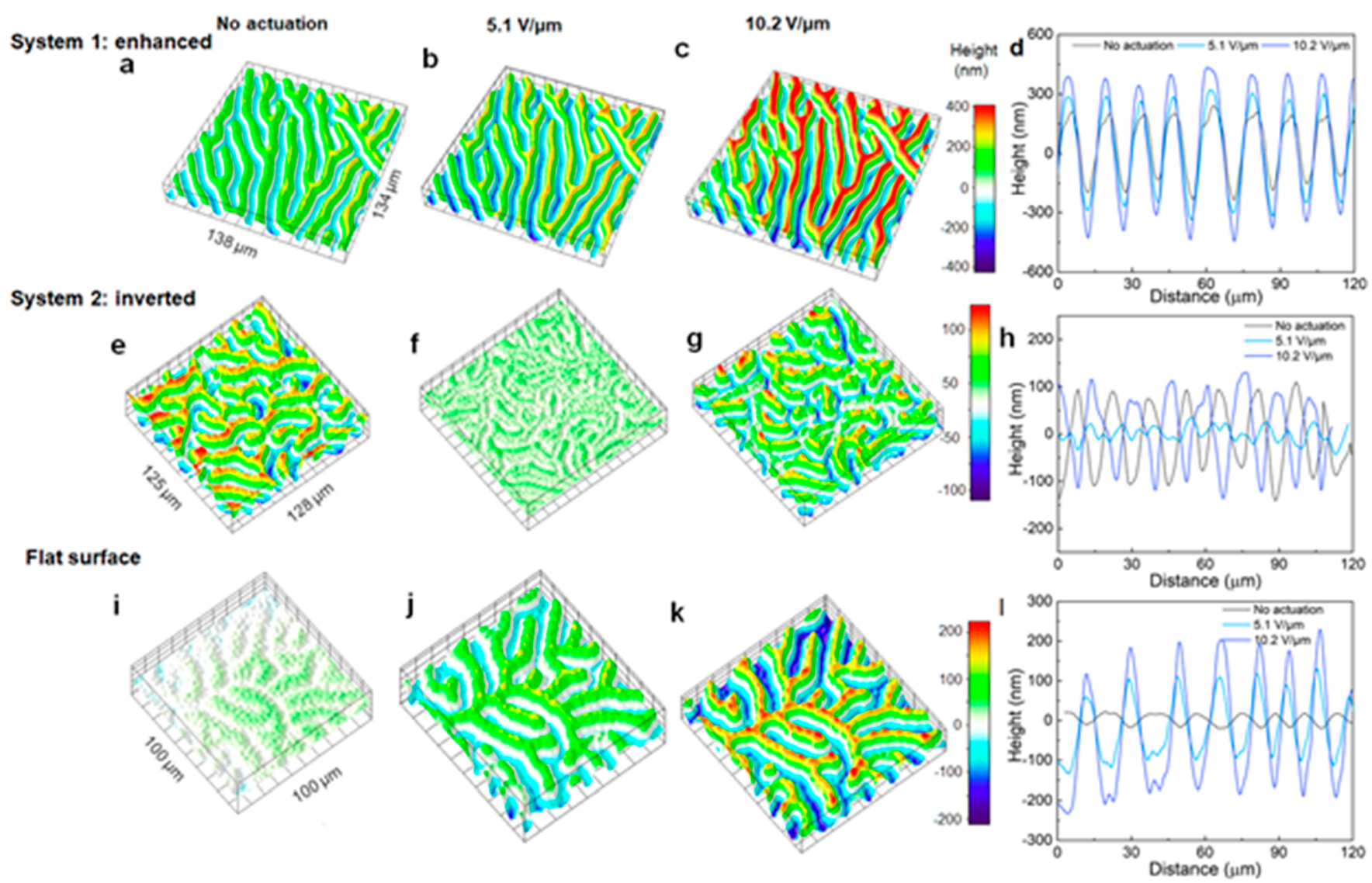

Figure 7. Topographical deformation of three types of coatings by electrical actuation. (a-d) Topographies of system I coating and corresponding $2 \mathrm{D}$ surface profiles. The amplitude of the surface corrugation increases when actuated. $(\mathrm{e}-\mathrm{h})$ Topographies of system II coating and corresponding 2D surface profiles. The amplitude of the surface corrugation goes to close to zero values at $5.1 \mathrm{~V} / \mu \mathrm{m}$, after which it inverts at an increased electrical field $(10.2 \mathrm{~V} / \mu \mathrm{m})$. (i-l) Topographies of an initially flat coating and corresponding $2 \mathrm{D}$ surface profiles. The flat surface turns to a corrugated state when actuated.

As for the influence of UV intensity for the initiation of polymerization on the height difference $h$, the evaluation was carried out with controlling the dichroic dye concentration $(1.2 \mathrm{wt} \%)$ and a fixed polymerization temperature $\left(30^{\circ} \mathrm{C}\right)$. In the range from 0.2 to $40 \mathrm{~mW} \mathrm{~cm} \mathrm{~cm}^{-2}$, a maximum height difference was observed at $5 \mathrm{~mW} \mathrm{~cm} \mathrm{~cm}^{-2}$ (Figure 6b) which can be explained in terms of polymerization rate versus diffusion time. Within the nematic phase range, the larger height difference is observed at higher polymerization temperatures due to the higher diffusion rate of LC monomers. ${ }^{42}$ (Figure 6c) By varying the chiral dopant concentration in the monomer mixture, samples with different fingerprint pitches were fabricated. The height difference $h$ has a larger absolute value for samples with larger fingerprint pitches (Figure 6d) as more materials participate in the diffusion process.

As the surface corrugation is influenced by polymerizationinduced diffusion of the various monomers to the highintensity area, it is of interest whether the local chemical composition will change as well. In order to estimate this effect, especially the diffusion of the faster reacting diacrylate molecule 2, we measure the local moduli by AFM (Figure S1). For the samples without dye, the topographically higher planar domains were found to have a slightly lower modulus (2.4 $\mathrm{GPa})$ than the homeotropic domains $(2.9 \mathrm{GPa})$. Although in line with the expectation of a somewhat higher modulus along the director, this difference is relatively small. In contrast, in the system II coating where the same mixture is polymerized in the presence of the dichroic dye, the local modulus of planar domains $(3.5 \mathrm{GPa})$ is $52 \%$ higher than that of the homeotropic domains $(2.3 \mathrm{GPa})$. This indicates that the much smaller LC monoacrylates diffuse faster to the high-intensity area, leaving a higher cross-link density in the lower planar domains.

3.4. Actuated Deformation of the Corrugated Fingerprints. We described earlier that fingerprint LCN coatings can be modulated by an in-plane electric field. ${ }^{22,43}$ The modulation typically proceeds on a time scale of several seconds. In relation to this work, it would be of interest how the fingerprint system I and system II coating would behave differently. As described earlier, the mechanism of the topographical surface deformation is based on the dynamic change of the scalar order parameter, ${ }^{19,22,44}$ because of which the homeotropic domains tend to shrink and planar domains tend to expand in the direction normal to the surface. As the initial surface landscapes of these coatings are different, we can afford different topographical deformation modes correspondingly. In detail, when actuated with the in-plane AC electric field which is generated with the interdigitated electrodes (Figure 1c), in system I coating, the height difference between the initially higher planar domains and the lower homeotropic domains becomes larger, making the surface more corrugated. The height difference $\mathrm{h}$ increases from $\sim 400 \mathrm{~nm}$ to $\sim 800 \mathrm{~nm}$ when actuated with $10.2 \mathrm{~V} / \mu \mathrm{m}$ AC electric field $(900 \mathrm{kHz}$ )(Figure 7a-d). Interestingly, system II coatings exhibit a different surface topographical response. With the homeotropic 
domains being initially higher than planar domains, system II coating first transforms to a relatively flat surface when actuated with $5.1 \mathrm{~V} / \mu \mathrm{m}$ AC electric field, and then adapts a corrugated surface with inversed surface topography when actuated with a larger electric field $(10.2 \mathrm{~V} / \mu \mathrm{m})$ (Figure $7 \mathrm{e}-\mathrm{h})$. For the initially flat coatings which can be obtained by tuning the concentration of the dichroic dye and UV light intensity during polymerization (Figure S2), the flat surface turns into a corrugated state with $\mathrm{h} \sim 370 \mathrm{~nm}$ (Figure 7i-1). These different kinds of topographical deformation are promising for various potential applications, for instance for the dynamic removal of debris from surfaces ${ }^{19,28}$ or to affect the roughnesscontrolled wettability when actuated with the electric field (Figure S3).

\section{CONCLUSIONS}

In summary, we have shown methods to control the topographies of fingerprint LCN coatings using the dichroic dye and dichroic initiator. By controlling experimental parameters, we can tune the surface roughness with designated landscapes or with close to a flat surface. Moreover, we have control over the directionality of the molecular orientation in the hills and valleys of the corrugations which have prospects for adhesion/release properties of these surfaces and their surface wetting behavior.Corresponding experimental parameters influencing the height difference are systematically investigated, including the concentration of dichroic molecules, UV light intensity and polymerization temperature. Further we have demonstrated distinct topographical deformation modes of fingerprint LCN coating surfaces when actuated: system I coatings exhibit enhanced surface corrugations when actuated, whereas system II coating first undergoes a transition to a relatively flat surface and then affording an inversed topography when further actuated with larger electric field strength, and the coating with relatively flat surface becomes corrugated when actuated. We envision that this mask-free method to control surface topography can be expanded to stimuli-responsive liquid crystalline coatings with predesigned alignments beyond the fingerprint configuration. Moreover, the principle is universal for other coatings with domains of different molecular alignment, as obtained, for instance, by polymerization of LC monomers at substrates with patterned alignment layers.

\section{ASSOCIATED CONTENT}

\section{S Supporting Information}

The Supporting Information is available free of charge on the ACS Publications website at DOI: 10.1021/acsami.9b11928.

Flat surface mediated by material diffusion and polymerization shrinkage; contact angle change during electrical actuation; AFM topographic images and correlated modulus images measured with nanoindentation mode (PDF)

\section{AUTHOR INFORMATION}

\section{Corresponding Author}

* Email: d.liu1@tue.nl.

ORCID $\odot$

Julius G. Vancso: 0000-0003-4718-0507

Danqing Liu: 0000-0001-8830-0443

\section{Notes}

The authors declare no competing financial interest.

\section{ACKNOWLEDGMENTS}

This work is supported by the European Research Council under ERC Advanced Grant 66999 (VIBRATE), the framework of the 4TU.HighTech Materials research program 'New Horizons in designer materials', and NWO VENI grant 15135. We acknowledge Prof. Albert Schenning for helpful discussions. Jeffrey N. Murphy is acknowledged for help in processing interferometric data.

\section{REFERENCES}

(1) Bhushan, B.; Jung, Y. C.; Koch, K. Micro-, Nano- and Hierarchical Structures for Superhydrophobicity, Self-Cleaning and Low Adhesion. Philos. Trans. R. Soc., A 2009, 367 (1894), 16311672.

(2) Guan, W.-S.; Huang, H.-X.; Chen, A.-F. Tuning 3d Topography on Biomimetic Surface for Efficient Self-Cleaning and Microfluidic Manipulation. J. Micromech. Microeng. 2015, 25 (3), 035001.

(3) Hammock, M. L.; Chortos, A.; Tee, B. C. K.; Tok, J. B. H.; Bao, Z. 25th Anniversary Article: The Evolution of Electronic Skin (ESkin): A Brief History, Design Considerations, and Recent Progress. Adv. Mater. 2013, 25 (42), 5997-6038.

(4) Eelkema, R.; Pollard, M. M.; Vicario, J.; Katsonis, N.; Ramon, B. S.; Bastiaansen, C. W. M.; Broer, D. J.; Feringa, B. L. Molecular Machines: Nanomotor Rotates Microscale Objects. Nature 2006, 440 (7081), 163-163.

(5) Li, J.; Hou, Y.; Liu, Y.; Hao, C.; Li, M.; Chaudhury, M. K.; Yao, S.; Wang, Z. Directional Transport of High-Temperature Janus Droplets Mediated by Structural Topography. Nat. Phys. 2016, 12, 606.

(6) Ben, S.; Tai, J.; Ma, H.; Peng, Y.; Zhang, Y.; Tian, D.; Liu, K.; Jiang, L. Cilia-Inspired Flexible Arrays for Intelligent Transport of Viscoelastic Microspheres. Adv. Funct. Mater. 2018, 28 (16), 1706666.

(7) Shahsavan, H.; Yu, L.; Jakli, A.; Zhao, B. Smart Biomimetic Micro/Nanostructures Based on Liquid Crystal Elastomers and Networks. Soft Matter 2017, 13 (44), 8006-8022.

(8) Liu, D.; Broer, D. J. Self-Assembled Dynamic 3d Fingerprints in Liquid-Crystal Coatings Towards Controllable Friction and Adhesion. Angew. Chem., Int. Ed. 2014, 53 (18), 4542-4546.

(9) Park, H.-H.; Seong, M.; Sun, K.; Ko, H.; Kim, S. M.; Jeong, H. E. Flexible and Shape-Reconfigurable Hydrogel Interlocking Adhesives for High Adhesion in Wet Environments Based on Anisotropic Swelling of Hydrogel Microstructures. ACS Macro Lett. 2017, 6 (12), $1325-1330$.

(10) Autumn, K.; Liang, Y. A.; Hsieh, S. T.; Zesch, W.; Chan, W. P.; Kenny, T. W.; Fearing, R.; Full, R. J. Adhesive Force of a Single Gecko Foot-Hair. Nature 2000, 405, 681.

(11) Li, F.; Hou, H.; Yin, J.; Jiang, X. Near-Infrared LightResponsive Dynamic Wrinkle Patterns. Science Advances 2018, 4 (4), eaar5762.

(12) Ohzono, T.; Suzuki, K.; Yamaguchi, T.; Fukuda, N. Tunable Optical Diffuser Based on Deformable Wrinkles. Adv. Opt. Mater. 2013, 1 (5), 374-380.

(13) Lee, S. G.; Lee, D. Y.; Lim, H. S.; Lee, D. H.; Lee, S.; Cho, K. Switchable Transparency and Wetting of Elastomeric Smart Windows. Adv. Mater. 2010, 22 (44), 5013-5017.

(14) Shrestha, M.; Asundi, A.; Lau, G.-K. Smart Window Based on Electric Unfolding of Microwrinkled Tio2 Nanometric Films. ACS Photonics 2018, 5 (8), 3255-3262.

(15) ter Schiphorst, J.; Coleman, S.; Stumpel, J. E.; Ben Azouz, A.; Diamond, D.; Schenning, A. P. H. J. Molecular Design of LightResponsive Hydrogels, for in Situ Generation of Fast and Reversible Valves for Microfluidic Applications. Chem. Mater. 2015, 27 (17), 5925-5931. 
(16) Feng, W.; Broer, D. J.; Liu, D. Combined Light and Electric Response of Topographic Liquid Crystal Network Surfaces. Adv. Funct. Mater. 2019, O (0), 1901681.

(17) De Haan, L. T.; Sánchez-Somolinos, C.; Bastiaansen, C. M. W.; Schenning, A. P. H. J.; Broer, D. J. Engineering of Complex Order and the Macroscopic Deformation of Liquid Crystal Polymer Networks. Angew. Chem., Int. Ed. 2012, 51 (50), 12469-12472.

(18) Ahn, S.-k.; Ware, T. H.; Lee, K. M.; Tondiglia, V. P.; White, T. J. Photoinduced Topographical Feature Development in Blueprinted Azobenzene-Functionalized Liquid Crystalline Elastomers. Adv. Funct. Mater. 2016, 26 (32), 5819-5826.

(19) Babakhanova, G.; Turiv, T.; Guo, Y.; Hendrikx, M.; Wei, Q.-H.; Schenning, A. P. H. J.; Broer, D. J.; Lavrentovich, O. D. Liquid Crystal Elastomer Coatings with Programmed Response of Surface Profile. Nat. Commun. 2018, 9 (1), 456

(20) Ware, T. H.; McConney, M. E.; Wie, J. J.; Tondiglia, V. P.; White, T. J. Voxelated Liquid Crystal Elastomers. Science 2015, 347 (6225), 982.

(21) Aharoni, H.; Xia, Y.; Zhang, X.; Kamien, R. D.; Yang, S. Universal Inverse Design of Surfaces with Thin Nematic Elastomer Sheets. Proc. Natl. Acad. Sci. U. S. A. 2018, 115 (28), 7206.

(22) Feng, W.; Broer, D. J.; Liu, D. Oscillating Chiral-Nematic Fingerprints Wipe Away Dust. Adv. Mater. 2018, 30 (11), 1704970.

(23) Liu, D.; Tito, N. B.; Broer, D. J. Protruding Organic Surfaces Triggered by in-Plane Electric Fields. Nat. Commun. 2017, 8 (1), 1526.

(24) Gelebart, A. H.; Jan Mulder, D.; Varga, M.; Konya, A.; Vantomme, G.; Meijer, E. W.; Selinger, R. L. B.; Broer, D. J. Making Waves in a Photoactive Polymer Film. Nature 2017, 546 (7660), 632-636.

(25) Yao, Y.; Waters, J. T.; Shneidman, A. V.; Cui, J.; Wang, X.; Mandsberg, N. K.; Li, S.; Balazs, A. C.; Aizenberg, J. Multiresponsive Polymeric Microstructures with Encoded Predetermined and SelfRegulated Deformability. Proc. Natl. Acad. Sci. U. S. A. 2018, 115 (51), 12950

(26) Yu, Y.; Nakano, M.; Ikeda, T. Photomechanics: Directed Bending of a Polymer Film by Light. Nature 2003, 425 (6954), 145145.

(27) Lv, J.-a.; Liu, Y.; Wei, J.; Chen, E.; Qin, L.; Yu, Y. Photocontrol of Fluid Slugs in Liquid Crystal Polymer Microactuators. Nature 2016, 537 (7619), 179-184.

(28) Bisoyi, H. K.; Li, Q. Light-Driven Liquid Crystalline Materials: From Photo-Induced Phase Transitions and Property Modulations to Applications. Chem. Rev. 2016, 116 (24), 15089-15166.

(29) Wani, O. M.; Zeng, H.; Priimagi, A. A Light-Driven Artificial Flytrap. Nat. Commun. 2017, 8, 15546.

(30) Ma, S.; Li, X.; Huang, S.; Hu, J.; Yu, H. A Light-Activated Polymer Composite Enables on-Demand Photocontrolled Motion: Transportation at the Liquid/Air Interface. Angew. Chem., Int. Ed. 2019, 58 (9), 2655-2659.

(31) Lan, R.; Sun, J.; Shen, C.; Huang, R.; Zhang, L.; Yang, H. Reversibly and Irreversibly Humidity-Responsive Motion of Liquid Crystalline Network Gated by $\mathrm{SO}_{2}$ Gas. Adv. Funct. Mater. 2019, 29 (23), 1900013.

(32) Urbach, W.; Rondelez, F.; Pieranski, P.; Rothen, F. Marangoni Effect in Nematic Liquid Crystals. J. Phys. (Paris) 1977, 38 (10), $1275-1284$.

(33) Hikmet, R. A. M.; Zwerver, B. H.; Broer, D. J. Anisotropic Polymerization Shrinkage Behaviour of Liquid-Crystalline Diacrylates. Polymer 1992, 33 (1), 89-95.

(34) Zheng, Z.-g.; Li, Y.; Bisoyi, H. K.; Wang, L.; Bunning, T. J.; Li, Q. Three-Dimensional Control of the Helical Axis of a Chiral Nematic Liquid Crystal by Light. Nature 2016, 531 (7594), 352-356.

(35) Wang, H.; Bisoyi, H. K.; Urbas, A. M.; Bunning, T. J.; Li, Q. Reversible Circularly Polarized Reflection in a Self-Organized Helical Superstructure Enabled by a Visible-Light-Driven Axially Chiral Molecular Switch. J. Am. Chem. Soc. 2019, 141 (20), 8078-8082.
(36) Qin, L.; Gu, W.; Wei, J.; Yu, Y. Piecewise Phototuning of SelfOrganized Helical Superstructures. Adv. Mater. 2018, 30 (8), 1704941.

(37) Chen, P.; Ma, L.-L.; Hu, W.; Shen, Z.-X.; Bisoyi, H. K.; Wu, S.B.; Ge, S.-J.; Li, Q.; Lu, Y.-Q. Chirality Invertible Superstructure Mediated Active Planar Optics. Nat. Commun. 2019, 10 (1), 2518.

(38) Li, J.; Bisoyi, H. K.; Tian, J.; Guo, J.; Li, Q. Optically Rewritable Transparent Liquid Crystal Displays Enabled by Light-Driven Chiral Fluorescent Molecular Switches. Adv. Mater. 2019, 31 (10), 1807751.

(39) Sun, J.; Lan, R.; Gao, Y.; Wang, M.; Zhang, W.; Wang, L.; Zhang, L.; Yang, Z.; Yang, H. Stimuli-Directed Dynamic Reconfiguration in Self-Organized Helical Superstructures Enabled by Chemical Kinetics of Chiral Molecular Motors. Advanced Science 2018, 5 (2), 1700613.

(40) Meyer, E. Atomic Force Microscopy. Prog. Surf. Sci. 1992, 41 (1), 3-49.

(41) Proksch, R.; Schäffer, T. E.; Cleveland, J. P.; Callahan, R. C.; Viani, M. B. Finite Optical Spot Size and Position Corrections in Thermal Spring Constant Calibration. Nanotechnology 2004, 15 (9), $1344-1350$

(42) Imura, H.; Okano, K. Temperature Dependence of the Viscosity Coefficients of Liquid Crystals. Jpn. J. Appl. Phys. 1972, $11(10), 1440$.

(43) Feng, W.; Liu, D.; Broer, D. J. Electric Field Switched Surface Topography of Fingerprint Liquid-Crystal Network Polymer Coating; SPIE: 2018; Vol. 10555

(44) Liu, Y.; Xu, B.; Sun, S.; Wei, J.; Wu, L.; Yu, Y. Humidity- and Photo-Induced Mechanical Actuation of Cross-Linked Liquid Crystal Polymers. Adv. Mater. 2017, 29 (9), 1604792. 